\title{
The Relevance of Football Curriculum in Same Selected Zone of Ethiopian Secondary Schools
}

\author{
TALILA LEGESE ANBASE \\ Lecturer at Madda Walabu University, Natural and Computational Science College \\ Department of Sport Science, BALE ROBE, ETHIOPIA
}

\begin{abstract}
The purpose of this study was to assess the relevance of Football Curriculum (Physical Education) in Some selected of Ethiopian's Secondary. Accordingly, it examined the curriculum relevance in football course. To accomplish this purpose across sectional descriptive survey design, which is supplemented by qualitative research, was employed. The study was carried out in selected eight secondary schools of East Showa Zone. The 16 teachers were selected purposively. Three hundred and fifty seven (357) students were included in the study using purposive sampling techniques from top 10 students. Seven schools principals were also included in the study by using census. Questionnaire was the main instrument of data collection. Interview and observation were also utilized to substantiate the data gained through the questionnaire. Percentage was employed to analyze the quantitative data, while qualitative data which was obtained through open-ended questions, interview and observation were analyzed using thematic analysis. The findings in this Study demonstrated that the program length given for football teaching is not sufficient to produce the expected knowledge \& skills. Similarly, the existing program would not ensure the students to possessing basic knowledge and background about football. Based on the findings, it is possible to conclude that, the implementation of football curriculum in the secondary schools of East Showa Zone were low. The point of the recommendations include: additional time is required to fulfill course objectives and the curriculum needs more modification.
\end{abstract}

DOI: $10.7176 / \mathrm{JTHS} / 50-02$

Publication date:September $30^{\text {th }} 2020$

\subsection{Introduction of the Study}

The football programs in schools should be enjoyable and provide opportunities for students to develop a positive association with physical activity. Through this students are given the opportunity to develop a variety of physical fitness such as endurance, strength speed, and agility and acquire the concepts and skills that will enable them to participate in other sports and games both for leisure and competition. In addition, football course provides a natural platform and valuable opportunities to develop self-management skills, social and co-operative skills, and build a good character. It serves to complement other educational areas in promoting the desired outcomes of education. In particular, football programs in school help to cultivate healthy habits, teamwork, resilience and techniques of the games (Luxbacher, 1991).

The other physical and psychosocial benefit of school football programs involvement facilitates cardiovascular fitness, weight control, muscular strength, muscular endurance, flexibility, and healthy bone structure. In addition to that physical activity habits develop during childhood and adolescence are associated with physical activity habits in adulthood (Baronowski et al., 1992).

Today, the football game provides access to programs, which serve hundreds of thousands of young people all over the world. The movement is a catalyst for innovation and social investment for various sectors of society and it is increasingly gain in recognition and attracting new resources and expertise. The football course philosophy is to maximize the potential of football in making a concrete contribution to sustainable development (VIDC, 2011).

So, football has become a vital instrument for hundreds of social development programs run by nongovernmental and community based organizations all around the world which providing children and young people with valuable tools to actively make a difference in their own lives. By addressing the most pressing issues in each community, football-teaching programs are contributing to positive social change on a global scale. In 2005, FIFA and street football world jointly began to bring such organizations together, strengthen their programs through direct support and increase their visibility. Football creates a unique and global movement through which the power of football is used as a force for sustainable social development. With its many successes on the ground, its global reach and the strong commitment of its founders, the football game movement has become an attractive platform for public and private sectors, civil society and multilateral development institutions to invest in a sustainable way and develop innovative partnerships for social development (Baronowski, Bar-Or, Bricker, , Bouchard and Washington, 1992).

\subsection{Statement of the Problems}

The invention of different kinds of games activities with no doubt had a profound effect on the current level of 
physical education as well as on the football development. Today football is recognized as one of the major parts of physical education program in every high school and is incorporated in the curriculum of Ethiopian education Furthermore, to the best knowledge of the researcher, there is scarcity of studies which focused on the issue in secondary schools of East Showa Zone of Ethiopia.. Therefore, all these initiated the researcher to investigate the research on practices and challenges of football teaching in secondary schools of East Showa Zone. In light of this the study tried to answer the following basic research questions:

\subsection{Basic research question}

$>$ To what extent the football curriculum is relevant in secondary schools?

\subsection{Objective of the Study}

The objective of this study was to investigate the extent to which the football curriculum is relevant in secondary schools in East Showa zone of Ethiopia.

\subsection{Significance of the Study}

The football teaching-learning program needs to be emphasized by the government and educational experts to make an investigation in identifying the problems that hinder its practices and development in school and to recommend possible solution. Thus, the results of the study have the following contributions. These are to:

a) Identify the strength and weaknesses of football curriculum and prospects of football teaching in secondary schools of East Showa Zone, Ethiopia. Thus the responsible body would take corrective action to solve the problems.

b) It will generate alternatives for the improvement of football curriculum through the stated recommendation.

c) Fill the knowledge gap about the football teaching-learning approach, build consensus and raise awareness of stakeholders for better practices.

d) It contributes to the improvement of quality education by initiating responsible parties in football development program.

e) It encourage physical education teachers school principals, woreda education office experts and sport commission as well as Zone education district to take actions against problems faced in football-teaching.

f) Kindle other researchers' interest to conduct further study on the topic.

\subsection{Delimitations of the Study}

The research was delimited in both conceptually and geographically. Regarding to content, this research was limited to investigate the extent to which the football curriculum is relevant in secondary schools in East Showa zone of Ethiopia. Geographically the scope of this study also limited to8 secondary schools of government school at East Showa Zone, specifically grade 10. This means it did not include grade 9, primary schools and nongovernmental schools found under the study area. Therefore, the finding of this research was generalized for secondary schools (grade 10) of East Showa Zone without considering non-governmental secondary school.

\subsection{Limitations of the Study}

Even though the research was attained its objectives, there were some inescapable limitations. First, due to the limit of time, finance and material resources; this research did not incorporate all the secondary schools of East Showa Zone. The assessment was run by focusing on the 8 government secondary schools. It did not include the non-governmental secondary schools. In addition to these, the data gathering process were so difficult because of the large number of population and the location of the schools. Furthermore, the lack of similar research done on the issue investigated in the studied area hindered the researcher from consulting more findings in the literature as well as in the discussion part.

\subsection{Organization of the paper}

This study was organized into five chapters. The first chapter deals with introduction of the study, statement of the problem, objectives of the study, significance of the study, delimitations of the study, limitation of the study, and operational definition of terms. The second chapter presents review of related literatures. Chapter three presents research design and methodology including the sources of data, the study population, sample size and sampling technique, procedures of data collection, data gathering tools and methodology of data analysis. The fourth chapter deals with data presentation, analysis and interpretation. The final chapter presents summary, conclusions and recommendations of the study.

\section{RESEARCH METHODS AND MATERIALS}

This part of the research presents the methodological aspects of the research, which includes research design, 
research method, study population, sample size and sampling techniques, data collecting instruments, data analysis and interpretations and also ethical considerations.

\subsection{Research Design}

Research design is the plan of action that links the philosophical assumptions to specific methods (Creswell \& Planoclark, 2007). Therefore in order to assess the current relevance of Football Curriculum in secondary school and thereby recommend constructive ideas, the cross-sectional descriptive study design was employed. This is because; the cross sectional descriptive study design is used to gather information from a population at a single time (Gratton \& Jones, 2004).

\subsection{Research Method}

Method is a style of conducting a research work, which is determined by the nature of the problem (Singh, 2006). So, in this study, both quantitative and qualitative approaches were used to get reliable result assessing the current relevance of Football Curriculum in secondary school. The collection of quantitative data was in a formal, structured and rigid manner. The qualitative approach was also incorporated in the study to validate and triangulate the quantitative data.

\subsection{Sources of Data}

To achieve the stated objectives, date was collected from physical education teachers, students and school principals. The decision to use these subjects as a source of data was based on the expectation that, they have a better experience and information about the relevance of Football Curriculum in secondary schools.

\subsection{The Study Site}

East Showa Zone is one of the twenty-four Zones in Oromia Regional State of Ethiopia, which is bordered on the south by the Arsi zone, on the west by west Arsi Zone, on the northeast by the Amara Reginal state and on East by the Afar Regional state and Awash River. Adama is the capital city of the zone. It is found on 99 KM distance from Addis Ababa to East. East Showa Zone comprises ten Woredas; Adama, Adaa, A/Tulu, Bora, Boset, Dugeda, Gumbichu, Libancukala, Lume, Fantale and three town administrations; Batu, Mojo and Matahara town. Total numbers of government secondary schools in the Zone are sixteen (16).

\subsection{Target Population}

Population is the entire group of people to which a researcher intends the results of a study to apply (Aron \&Coups, 2008). Therefore, the target populations of this study were physical education teachers, students and the respective secondary schools principals of the East Showa Zone. Specifically, secondary schools physical education teachers (32), secondary schools principals (16), and secondary schools students (5000) with the total populations of 5048

\subsection{Sample size and sampling Techniques}

In this study, both probability (lottery sampling) and non-probability (purposive) sampling technique were employed to obtain the representative sample units. Out of the 13 secondary schools of ten woredas, six secondary schools (AdamiTullu, Boset, Bulbula, Dugda, Lume\&Wanji) were selected through simple random sampling technique (lottery method) while two town administration secondary schools (Mojo \&Batu) were selected purposively. Table 1 presents summary of the sample schools.

Table 1: Summary of the Sample Schools

\begin{tabular}{|c|c|c|}
\hline Name of the selected sample schools & Total & Sampling technique \\
\hline $\begin{array}{l}\text { Adami Tullu, Boset, Bulbula, Dugda, Lume \& } \\
\text { Wanji }\end{array}$ & 6 & $\begin{array}{l}\text { Simple random sampling } \\
\text { method) }\end{array}$ (lottery \\
\hline Mojo \& Batu & 2 & Purposively \\
\hline Total & 8 & \\
\hline
\end{tabular}

The researcher decided to use these sample schools due to the available financial and material resources to conduct the study effectively. Since, most secondary schools in East Showa Zone have relatively similar standards like infrastructure, facility, availability, geographical place and weather condition. Thus, selecting them randomly was promoted their representativeness for the whole secondary school of the Zone.

Regarding to the participants, the total numbers of physical education teachers in the eight selected secondary schools are 16. Hence, the researcher used these 16 teachers as the representatives' samples for teachers as it is and the selected eight secondary schools' principles which are eight (8) in number were taken purposively. Finally, 357 students were selected from eight secondary schools based on the Morgan sample size determination table. Furthermore, regarding student respondents the researcher select grade 10 students and from these students the researcher took representative students both male and female from each section purposively top 10 students. Because, the researcher believed that, these students have better experience, knowledge, understanding and 
adequate information about the practice and challenge of football teaching-learning process in their schools. Thus, they provided relevant and adequate information.

Supporting this, (Ball, 1990 ) suggested that " purposive sampling is used in order to access 'knowledgeable people', i.e. those who have in-depth knowledge about particular issues, may be by virtue(good quality) of their professional role, understanding, power and experiences". So, in general 381 individuals were included in the study as the sample to extract sufficient evidence.

To determine the sample size of students from each secondary school, the stratified formula of William (1977) was utilized.

Table 2: Population, Total sample size\& Sampling Techniques

\begin{tabular}{|l|l|l|l|l|}
\hline Participants & Population & Sample size & Sampling techniques & Justification \\
\hline Students & 5000 & 357 & $\begin{array}{l}\text { Purposively top } 10 \\
\text { students }\end{array}$ & To make it manageable \\
\hline Teachers & 32 & 16 & Purposive & Available \\
\hline Principals & 16 & 8 & Purposive & Available \\
\hline Total & 5048 & 381 & & \\
\hline
\end{tabular}

\subsection{Instruments of Data Collection}

In order to acquire the necessary information from the study participants, three types of data collecting instruments were employed. These are: Questionnaire, interview \& observation.

\subsubsection{Questionnaire}

Both closed and open ended questionnaire were employed to collect quantitative and qualitative data from selected students \& teachers. This is because questionnaire is convenient to conduct survey and to acquire necessary information from large number of respondents with short period of time. Furthermore, it save time and expense and also provides a high proportion of usable response (Best \& Kahn, 2003). The questionnaire was prepared in English language, because all of the respondents have the necessary skills to read, write and understand the concepts that were incorporated.

The researcher and assistance data collectors dispatched and collected the questionnaire at each school. To make the data collection procedure smart and clear from confusions, the data collectors were properly oriented about the data collection procedures and the researcher closely monitors the process. The questionnaire has two parts. The first part of the questionnaire describes the respondents' background information like gender, age, level of education and work experience (for teachers) and name of School, age and gender (for students). The second and the largest part of the questionnaire contain the whole number of closed and open-ended questions that address the basic questions of the study.

\subsubsection{Interview}

An interview is the verbal questions asked by the interviewer and verbal responses provided by the interviewee (Gall et al., 2007). For this study, Semi-structured type of interview which prepared in English language was used to gather in-depth qualitative data from schools principals (8) regarding football curriculum in secondary school.

\subsubsection{Observation}

The purpose of classroom and field observation was to obtain and acquire information on how do teachers implement and transmit knowledge and practical skills to their students in general and how to support students.

\subsection{Method of Data Analysis and Interpretation}

The data was analyzed both quantitatively and qualitatively. The analysis of the data was based on the responses collected through questionnaires, interview and observation. The data collected through closed ended questionnaires were filled in to SPSS version 16 and analysis was done. Then interpretation was made with help of percentage.

\subsection{Ethical Consideration}

Ethical considerations play a role in all research studies, and all researchers must be aware of and attend to the ethical considerations related to their studies. Thus the purpose of the study was explained to the participants and the researcher asked their permission to answer questions in the questionnaire or interview guide and the participants also informed that the information they provide is use only for the study purpose. Accordingly, researcher used the information from his participants only for the study purpose. In addition, the researcher ensured confidentiality through made the participants anonymous.

\section{Results}

- With regard to the curriculum evaluation the findings in this study demonstrated that the program length given for football teaching was not sufficient to produce required knowledge \& skills. Similarly the present program would not ensure the students to possessing basic knowledge and background about football. So 
the finding illustrated that additional time is required to fulfill course objectives.

- As the findings in this section indicated the sequencing of practice (order of subjects presented) within the curriculum were not properly addressed, all necessary learning objectives were not included within the subjects, theory and practice were not properly balanced in the curriculum and the finding result also, showed that there were areas of the course that needed to be revised or removed from the book. Because, the book did not considering the present revival of students' interest.

- As the findings in this domain indicated, the equipment and materials listed for the practical components of the course were unsatisfactory to deliver the program in appropriate manners.

- As the result of the study pointed out there were no the instructional reinforcements with appropriate technical inputs to enhance the participation of students in the secondary schools of East Showa Zone.

- The findings in this study showed that the instructional methods (theoretical \&practical) were not good to deliver the course. The duration of the course were inadequate to reinforce, and allow students to make a practical application of, the theoretical concepts already learned

- The study also suggested that, the school administration did not recognizes the importance of football as a subject in the overall school curriculum.

\section{Discussion}

- Concerning the relevance of the football curriculum in secondary schools of East Showa Zone, the findings of this study indicate that the curriculum design has a number of problems like, shortage of programs, sequence of practice \& theoretical parts, unsatisfactory equipment list in the curriculum and un reinforced instructions by technical in puts. Regarding to this, Mckernan (1991) suggested that to evaluate a physical education curriculum in any particular setting, the program must be viewed as having three basic components which are interrelated with program development - outcomes, activities and resources. So, since the football curriculum was not fulfilled the above theory, the curriculum needs more modification.

\section{Conclusions}

- Based on the findings in this study, it is clear that the football curriculum design has its own problems. That means the shortage of the time given for the course, sequencing of practice, limited learning objectives', unsatisfactory equipment listed in the course, lack of revision, inappropriate balance between theory and practices, lack of reinforcement during instruction, and negative attitudes of the school administration were the major problems of the football course curriculum. Therefore, the results clearly showed that there were the problems of the curriculum design in football course and these had the great impact on teaching-learning practice.

\subsection{Recommendation}

$>$ In order to make the curriculum effective, the curriculum should be revised. That means teachers, parent, non-governmental organizations, and other concerned governmental offices should be involved during the review of curriculum of football, which helps to balance theoretical and practical parts, as well as to avoid unnecessary things and to include necessary things in the textbook.

$>$ The shortage of time given for the course, the equipment listed in the course, and unrevised areas of the course should be corrected in order to make the course interesting.

$>$ The schools administration have to recognizes the importance of football as a subject in the overall school curriculum in order to encourage the teaching-learning practice in football course.

$>$ Finally, the researcher recommends a more detailed and comprehensive study in the area to strengthen the findings reported in this study.

\section{References}

Adams, J., Khan, H. T. A., Raeside, R. \& White, D. (2007). Research method for graduate business and social science students. USA: Sage Publications Inc

Aron, A., Aron, E. \& Coups, E. (2008).Statistics for the behavioral and social sciences. (4 ${ }^{\text {th }}$ ed.). USA: Pearson Education, Inc.

Baronowski, T., Bouchard, C., Bar-Or, O., Bricker, T.,Baronowski, T., Bouchard, C., Bar-Or, O., Bricker, T., Washington R.(1992) Assessment, prevalence, and cardiovascular benefits of physical activity and fitness in youth

Best, J. W. \&Kanh, J. V. (2003).Research in education. ( $9^{\text {th }}$ ed.). AsokeK.Ghosh, Prentice-Hall of India Private Ltd. New Delhi.

Best, J.W. (1970).Research in Education. Englewood Cliffs, NJ: Prentice Hall

Bredemeier, B., Weiss, M.R., Shields, D.L., Shewchuk, R.M. (1986). Promoting growth in a summer sports camp: The implementation of theoretically grounded instructional strategies. Journal of Moral Education, 15,212220. 
Bunker, D. and Thorpe, R., A. (1982).Model for the Teaching of Games in Secondary Schools in the Bulletin of Physical Education, Volume 18 No.1, Spring 1982

Bunker, B., \& Thorpe, R. (1986). The curriculum model. In R. Thorpe,

Bunker, D., \& Almond, L (Ed.), Rethinking games teaching (pp. 7-10). Loughborough: University of Technology, Loughborough

Buschner, C.A. (1994). Teaching children movement concepts and skills: becoming a master teacher.Champaign, IL: Human Kinetics.

Cohen, L., Manion, L. \& Morrison, K. (2007).Research Method in Education. $6^{\text {th }}$ Edition. Great Britain.MPG Books Ltd, Bodmin.

Côté, J., \& Hay, J. (2002).Children's involvement in sport: A developmental perspective.

Creswell, J. \& Planoclark, V. (2007). Designing and conducting mixed methods research.USA: Saga publication, Inc.

Deborach A. (1994).Curriculum and Instruction of the Secondary School Physical Education Experience.Mosby Company USA.

Dworkin, J. B., Larson, R., \& Hansen, D. (2003). Adolescents' accounts of growth experiences in youth activities. Journal of Youth and Adolescence, 32 (1),17-26.

Eccles, J.S., \& Barber, B.L. (1999). Student council, volunteering, basketball, or marching band: What kind of extracurricular involvement matters? Journal of Adolescent Research,

Ewing, M.E., \& Seefeldt, V. (1989).Participation and attrition patterns in American agency-sponsored and interscholastic sports: An executive summary. Final Report.

Fowler, J. (1996). Introduction to Statistics A Non-parametric Approach for the Social Sciences. New York, John Willy

Fuller, B.,Dellagnelo, L. (1999). How to Raise Children's Literacy? The influence of family, teacher, and classroom in Northeast Barazil. Comparative Education Review, 43(1),1-35.

Gibbins, S.L., Ebbeck, V., \& Weiss, M.R. (1995). Fair play for kids: Effects on the moral development of children in physical education. Research Quarterly for Exercise \& Sport, 66, 247-255.

Gratton, C., \& Jones, I. (2004). Research methods for sports studies. London: Routledge

Hansen, D., Larson, R., \& Dworkin, J. (2003). What adolescents learn in organized youth activities: A survey of self-reported developmental experiences. Journal of Research on Adolescence, 13 (1), 25-56.

Hellison, D. (1995). Teaching responsibility through physical activity. Champaign IL: Human Kinetics.

Hellison, D.,\& Walsh, X. (2002). Responsibility-based youth programs evaluation: Investigating the investigations. Quest, 54 (4), 292-307

Jackson L. Sherri (2009). Research Methods and Statistics. A Critical Thinking Approach (3rd ed). New York: Wadsworth

J.M. Silva \& D.E. Stevens (Eds.) Psychological foundations of sport (pp. 484-502). Ababa University: Ethiopia. (Un published Master's Thesis).band: What kind of extracurricular involvement matters? Journal of Adolescent. 